\title{
ANÁLISE DE UM CICLONE SEMI-ESTACIONÁRIO NA COSTA SUL DO BRASIL ASSOCIADO A BLOQUEIO ATMOSFÉRICO
}

\author{
MICHELLE SIMÕES REBOITA, CLARA MIHO NARUKAWA IWABE, \\ ROSMERI PORFÍRIO DA ROCHA E TÉRCIO AMBRIZZI
}

\author{
Universidade de São Paulo, Departamento de Ciências Atmosféricas, São Paulo, SP \\ reboita, cliwabe, rosmerir, ambrizzi@model.iag.usp.br \\ Recebido Dezembro 2008 - Aceito Julho 2009 \\ RESUMO
}

Na primeira semana de maio de 2008, durante quatro dias, um ciclone em superfície permaneceu semi-estacionário na costa da região sul do Brasil. Este sistema foi responsável por chuvas e ventos fortes no Rio Grande do Sul e Santa Catarina, os quais causaram muitos danos (queda de árvores, enchentes e desabamentos). O objetivo deste trabalho é avaliar o processo de formação e entender os mecanismos responsáveis pelo lento deslocamento do ciclone, já que a maioria dos ciclones nesta região possui deslocamento mais rápido. A equação de desenvolvimento de Sutcliffe mostrou que a advecção de vorticidade absoluta ciclônica na média troposfera e a advecção de ar quente na camada entre 1000-500 hPa foram mecanismos importantes para a ciclogênese. Neste período, o intenso aquecimento diabático também contribuiu para a ciclogênese, à medida que se contrapôs ao intenso resfriamento adiabático devido aos movimentos verticais ascendentes. A advecção de vorticidade absoluta ciclônica que favoreceu a ciclogênese esteve associada a um Vórtice Ciclônico em Altos Níveis (VCAN), que se formou numa região de anomalia de vorticidade potencial. O VCAN se manteve semi-estacionário e compôs o setor norte de um bloqueio do tipo dipolo. Tal bloqueio intensificou um anticiclone em superfície, situado a sul/leste do ciclone, o que contribuiu para o ciclone se manter semi-estacionário. O movimento atípico e lento do ciclone para sul, e em alguns períodos para sudoeste, esteve associado com advecções de vorticidade absoluta ciclônica na média troposfera e de ar quente no seu setor sul. Somente quando o bloqueio em níveis médios e a anomalia de vorticidade potencial em níveis médios/altos se enfraqueceram, o ciclone em superfície se afastou da costa sul do Brasil. Palavras-Chave: ciclogênese, VCAN, costa sul do Brasil

\begin{abstract}
ANALYSIS OF A SEMI-STATIONARY CYCLONE ON THE COAST OF SOUTHERN BRAZIL ASSOCIATED TO AN ATMOSPHERIC BLOCKING

On the first week of May 2008, during four days, a semi-stationary surface cyclone acted over the coast of southern Brazil. This system was responsible for large amount of rain and strong near surface winds over Rio Grande do Sul and Santa Catarina causing many damages (fallen trees, floodings and landslides). This work evaluated cyclone development process to understand the reasons for its slow displacement, once most cyclones developed in this region move faster. The Sutcliffe development equation showed that cyclonic absolute vorticity advection in middle troposphere, and positive thermal advection in layer between 1000-500 hPa were important mechanisms for cyclogenesis processes. In this same period, diabatic heating also contributes to cyclogenesis as far as it was opposite to adiabatic cooling due to strong upward movement. Cyclonic absolute vorticity advection which propitiated cyclogenesis was associated with an Upper Level Cyclonic Vortex (ULCV) developed in a potential vorticity anomaly region. The ULCV was semi-stationary and part of a blocking dipole pattern. This blocking intensified a surface anticyclone at south/east of the cyclone, contributing to the cyclone staying semi-stationary near the coast of southern Brazil. The slow and unusual surface cyclone movement to south and sometimes to southwest was associated with middle level cyclonic absolute vorticity and warm air advections in their southern sector. Only when middle levels blocking and middle/high levels potential vorticity anomaly weakened, surface cyclone moved away from the coast of Southern Brazil.
\end{abstract}

Keywords: cyclogenesis, ULCV, Brazilian south coast 


\section{INTRODUÇÃO}

Durante o ano observa-se o desenvolvimento e/ou a intensificação de ciclones na costa das regiões sul e sudeste do Brasil (Seluchi, 1995; Sinclair, 1996; Piva, 2001, Hoskins e Hodges, 2005, Reboita et al., 2005, Reboita, 2008). Do ponto de vista climatológico (Reboita, 2008), nesta área tanto a instabilidade frontal em superfície como a divergência a leste dos cavados transientes em níveis médios contribuem para as ciclogêneses. Reboita (2008) mostrou que tais cavados influenciam pouco a queda de pressão em superfície no período prévio às ciclogêneses, isto é, à medida que se deslocam do oceano Pacífico em direção ao Atlântico. Entretanto, ao se aproximarem da costa sul/sudeste do Brasil, intensificam-se e contribuem para a queda de pressão em superfície. Uma possível explicação para isso seria a interação do cavado transiente com o cavado semi-estacionário, resultante da influência da topografia dos Andes no escoamento de oeste (Satyamurty et al., 1980; Lenters e Cook, 1997).

As massas de ar frio, ao cruzarem o continente sulamericano (Marengo e Rogers, 2001), de latitudes altas em direção ao equador, geram gradientes horizontais de temperatura do ar, instabilizando a atmosfera e, na maioria das vezes, favorecendo ciclogêneses em superfície (Ford e Moore, 1990). Em algumas ocasiões, a costa sul/sudeste do Brasil sofre simultaneamente a influência dos cavados em níveis médios/altos e também de instabilidade frontal em superfície (Seluchi et al., 2001; Reboita, 2008), o que pode propiciar sistemas ciclônicos bastante intensos na baixa troposfera. Em outras ocasiões, com apenas um destes mecanismos atuando, ainda assim, pode ocorrer ciclogênese em superfície. De acordo com Reboita (2008), o transporte de umidade para a costa sul/ sudeste do Brasil também favorece a queda de pressão nesta área. Tanto o jato de baixos níveis a leste dos Andes, que flui da região amazônica para o sudeste da América do Sul (Marengo et al., 2004), como o anticiclone subtropical do Atlântico Sul (Seluchi, 1995), participam deste transporte de ar úmido. Com disponibilidade de umidade pode ocorrer precipitação e, nesse processo, a liberação de calor latente aquece a coluna atmosférica e intensifica a convergência na baixa troposfera (da Rocha, 1999; Vera et al. 2002). Simulações numéricas têm demonstrado que a liberação de calor latente contribui com parte significativa (entre 30-50\%) da taxa de aprofundamento de ciclones extratropicais (Kuo e Low-Nam, 1990; Kuo et al.,1991; Huo et al., 1996; da Rocha 1999). Além disso, contribui para reduzir o comprimento da onda baroclinicamente mais instável e o tempo de desenvolvimento dos sistemas (Bonatti e Rao, 1987). Portanto, tal processo termodinâmico, associado a um processo dinâmico (mesmo de fraca intensidade) favorece as ciclogêneses.
Como a costa sul/sudeste do Brasil é banhada pelas águas quentes da Corrente do Brasil, muitas vezes a transferência de calor latente e sensível do mar para a atmosfera atua como fonte diabática adicional nas ciclogêneses (Piva, 2001; Iwabe, 2008). Experimentos numéricos, em geral, mostram que na ausência destes fluxos os ciclones são mais fracos (Piva, 2001; Oda, 2005; Reboita, 2008). Entretanto, não é totalmente resolvido como tais fluxos atuam nas ciclogêneses, já que alguns autores (Kuo e Low-Nam, 1990; Reed e Simmons, 1991) obtiveram ciclones mais fracos no Atlântico Norte na presença de fluxos turbulentos na direção mar-ar. Estes experimentos mostraram redução dos gradientes horizontais de temperatura (redução da baroclinia) à medida que a transferência de calor (sensível e latente) do mar para atmosfera aqueceu o lado frio dos ciclones.

A presença de anomalias de vorticidade potencial (VP) na troposfera superior (Hoskins et al., 1985; Bluestein, 1993) também pode contribuir para ciclogêneses. $\mathrm{O}$ ar estratosférico, com altos valores de VP (forte estabilidade estática devido à ausência de movimentos convectivos e de turbulência), ao deslocar-se para a troposfera, uma região com menor estabilidade estática, induz vorticidade ciclônica. As anomalias de VP favorecem a formação (ou intensificação) de circulações ciclônicas na média e baixa troposfera de duas maneiras: a primeira associada ao efeito de stretching que induz vorticidade ciclônica sob a anomalia de VP, e a segunda propiciando circulação ciclônica em superfície a leste da primeira. Neste último caso, seguindo Hoskins et al. (1985), uma anomalia de VP em altos níveis, associada com um cavado de altos níveis, move-se para leste sobre anomalia positiva de temperatura em baixos níveis gerada por advecção térmica. Normalmente, as circulações induzidas por estas duas anomalias acoplamse e reforçam-se mutuamente, resultando em ciclogênese de superfície.

Anomalias de VP na alta troposfera estão freqüentemente associadas com o desprendimento de Vórtices Ciclônicos em Altos Níveis (VCANs - também conhecidos como baixas desprendidas) do escoamento de oeste. Esses vórtices possuem centros frios e são identificados através de isolinhas fechadas de altura geopotencial. Nieto et al. (2005) verificaram que 72,63\% dos VCANs identificados sobre a Europa estavam associados a anomalias de VP, sendo que $47,1 \%$ formaram baixas em superfície. As ciclogêneses na costa leste da América do Sul também sofrem influência de anomalias de VP. Por exemplo, Miky Funatsu et al. (2004) e Iwabe (2008) estudaram ciclones na costa do Uruguai e sul do Brasil, que se formaram associados a VCANs e anomalias de VP. A diferença entre os dois eventos estudados está no mecanismo que favoreceu a perturbação quente em baixos níveis. Enquanto em Miky Funatsu et al. (2004) este mecanismo foi a advecção de ar quente na baixa troposfera, em Iwabe (2008) o ciclone se desenvolveu sobre 
intensa advecção fria, mas com forte aquecimento diabático através da transferência de calor latente e sensível do oceano para atmosfera.

Os VCANs também são componentes de bloqueios atmosféricos do tipo dipolo (Rex, $1950 \mathrm{a}, \mathrm{b}$ ), onde um VCAN é encontrado meridionalmente em fase com um anticiclone localizado em latitudes mais altas. As regiões sob atuação de bloqueios atmosféricos apresentam condições de tempo duradouras, já que eles obstruem/modificam o deslocamento das ondas baroclínicas e, também, reduzem o cisalhamento vertical do vento. A transição de ciclone extratropical para o furacão Catarina em março de 2004 esteve associada a um bloqueio do tipo dipolo (McTaggart-Cowan et al., 2006) que criou uma circulação anômala com ventos de leste e propiciou o deslocamento do ciclone para oeste. À medida que o ciclone se deslocava para oeste encontrava cisalhamento vertical do vento mais fraco (propiciado pelo bloqueio dipolo), um mecanismo considerado importante para sua transição para furacão (McTaggart-Cowan et al., 2006).

Os ciclones que se formam na costa sul/sudeste do Brasil deslocam-se para leste ou sudeste com velocidade média de $9 \mathrm{~ms}^{-1}$, percorrem distâncias de aproximadamente $2700 \mathrm{~km}$ e possuem tempo de vida médio de 3 dias (Reboita, 2008). Na primeira semana de maio de 2008 , um ciclone se formou no extremo sul do estado de São Paulo (Figura 1a) e apresentou características distintas da climatologia, isto é, deslocou-se lentamente (velocidade média de $5 \mathrm{~ms}^{-1}$ ) para sul. Com isso, o sistema permaneceu por mais tempo nas regiões onde atuava, causando chuvas e ventos fortes nos estados do Rio Grande do Sul e Santa Catarina que produziram muitos estragos (queda de árvores, enchentes e desabamentos). Segundo informações disponíveis no portal da Defesa Civil do Estado do Rio Grande do Sul (http://www.defesacivil.rs.gov.br/) 76.995 pessoas, residentes em 18 municípios, foram atingidas por este ciclone. Diante do exposto, tem-se como objetivo investigar o processo de formação desse ciclone e discutir os mecanismos físicos que favoreceram o seu lento deslocamento.

\section{DADOS E METODOLOGIA}

Para o período de $1^{\circ}$ a 6 de maio de 2008 foram utilizadas a pressão ao nível médio do mar (PNMM), altura geopotencial, componentes zonal e meridional do vento, pseudo-velocidade vertical omega e umidade relativa da reanálise I do National Center for Environmental Prediction (NCEP - Kalnay et al., 1996). Estes dados possuem resolução horizontal de $2,5^{\circ}$ de latitude por $2,5^{\circ}$ de longitude em 17 níveis verticais de pressão (de 1000 a $10 \mathrm{hPa}$ ) e em quatro horários por dia $(0000,0600$, 1200 e 1800 UTC). Utilizaram-se ainda dados médios diários de magnitude e direção do vento com resolução horizontal de $0,25^{\circ}$ do QUIKSCAT (Dunbar et al., 2006). Imagens do satélite GOES-10 no canal infravermelho foram obtidas do Centro de Previsão de Tempo e Estudos Climáticos do Instituto Nacional de Pesquisas Espaciais (CPTEC-INPE www.cptec.inpe.br).

A formação do ciclone foi investigada através da análise dos termos da equação do desenvolvimento de Sutcliffe (Petterssen, 1956; Kousky e Elias, 1982) e da vorticidade potencial em coordenadas isobáricas (Reed, 1955). A equação de Sutcliffe permite avaliar os fatores entre a superfície e a média troposfera associados com o desenvolvimento e o deslocamento dos sistemas de pressão. Seguindo as idéias de Hoskins et al. (1985), a vorticidade potencial (VP) permite analisar a contribuição de perturbações na alta troposfera para o desenvolvimento de ciclogêneses em superfície a leste destas perturbações.

A equação de Sutcliffe (Equação 1) relaciona a variação local da vorticidade absoluta no nível de $1000 \mathrm{hPa}$ (termo 1A que indica a presença de ciclogênese ou anticiclogênese) com: advecção horizontal de vorticidade absoluta em $500 \mathrm{hPa}$ (termo 1B), valores integrados na camada entre 1000 a $500 \mathrm{hPa}$ de advecção horizontal de temperatura (termo $1 \mathrm{C}$ ), variação de temperatura por movimento vertical (termo 1D) e fontes diabáticas de calor (termo 1E).

$$
\begin{array}{ll}
\frac{\partial Q_{o}}{\partial t}=-(\vec{V} \cdot \vec{\nabla} Q)_{p}-\frac{R}{f} \nabla_{p}^{2} \int_{p}^{p_{o}}\left(A_{T}+S+H\right) d \ln p \\
\begin{array}{ll}
\text { 1A } \quad \text { IB } & \text { IC ID IE }
\end{array}
\end{array}
$$

Os termos da Equação 1 indicam:

Termo 1A: tendência da vorticidade absoluta em 1000 $\mathrm{hPa}$, sendo $\mathrm{Q}_{0}=\left(\zeta_{0}+\mathrm{f}\right)$ a vorticidade absoluta em $1000 \mathrm{hPa}, \zeta_{0}$ a vorticidade relativa e $\mathrm{f}$ a vorticidade planetária $(\mathrm{f}=2 \Omega \operatorname{sen} \phi)$.

Termo 1B: advecção horizontal de vorticidade absoluta em $500 \mathrm{hPa}$, onde Q é a vorticidade absoluta e $\overrightarrow{\mathrm{V}}$ é o vento horizontal, ambos em $500 \mathrm{hPa}$. É importante ressaltar que a advecção de vorticidade absoluta inclui a relativa, que contribui para deslocamento das ondas atmosféricas para leste nas latitudes médias, e a planetária que favorece deslocamento para oeste. Como a contribuição da vorticidade planetária é pequena nas latitudes médias para ondas de escala sinótica, predomina o efeito da vorticidade relativa indicando que as ondas se deslocam para leste.

Termo 1C: advecção de espessura ou de temperatura $A_{T}=-\vec{V} \cdot \vec{\nabla}_{\mathrm{p}} \mathrm{T}$ onde $\mathrm{T}$ é a temperatura do ar. Este termo também pode contribuir para o deslocamento do sistema, pois normalmente observa-se advecção de ar frio atrás e advecção de ar quente na frente do ciclone, o que favorece o deslocamento do sistema para leste-sudeste.

Termo 1D: termo relacionado ao movimento vertical, ou seja, estabilidade da coluna de ar: 


$$
S=-\omega\left(\frac{\partial T}{\partial p}-\frac{1}{\rho c_{p}}\right)
$$

onde $\omega$ é a pseudo-velocidade vertical, p a pressão atmosférica, $\rho$ a densidade do ar e $\mathrm{C}_{\mathrm{p}} \mathrm{o}$ calor específico à pressão constante $\left(1004 \mathrm{~J} \mathrm{~K}^{-1} \mathrm{~kg}^{-1}\right)$.

Termo 1E: taxa de aquecimento/resfriamento diabático

$$
H=\frac{1}{c_{p}} \frac{\overline{d H}}{d t}
$$

onde $\bar{H}$ é o calor diabático, calculado como o resíduo da equação da termodinâmica, i.e.,

$$
\frac{\partial T}{\partial t}=-\vec{V} \cdot \overrightarrow{\nabla_{\mathrm{p}}} T+\omega \frac{R T}{c_{p} p}+\omega \frac{\partial T}{\partial p}+\frac{1}{c_{p}} \frac{d H}{d t}
$$

$2 \mathrm{~A} \quad 2 \mathrm{~B} \quad 2 \mathrm{C} \quad 2 \mathrm{D} \quad 2 \mathrm{E}$

$\mathrm{Na}$ Equação 2, o termo 2A representa a variação local de temperatura, $2 \mathrm{~B}$ advecção horizontal de temperatura, $2 \mathrm{C}$ expansão/compressão adiabática, $2 \mathrm{D}$ advecção vertical de temperatura e, por fim, 2E é o termo diabático. Lembrando que $\mathrm{H}$ representa a soma dos processos radiativos, liberação de calor latente, calor sensível ou transporte turbulento.

Uma descrição detalhada da interpretação dos termos da equação de Sutcliffe é dada em Kousky e Elias (1982) e uma síntese para o Hemisfério Sul é apresentada na Tabela 1. O sinal de cada termo da equação favorável ou desfavorável ao desenvolvimento dos ciclones é dado na coluna ANÁLISE e o sinal aplicando o laplaciano é dado na coluna $\nabla^{2}$ (TERMO).

A VP em coordenadas isobáricas foi calculada como em Reed (1955):

$$
\mathrm{VP}=-\mathrm{g}\left[\left(\zeta_{\mathrm{p}}+\mathrm{f}\right) \frac{\partial \theta}{\partial \mathrm{p}}-\frac{\partial \theta}{\partial \mathrm{x}} \frac{\partial \mathrm{v}}{\partial \mathrm{p}}+\frac{\partial \theta}{\partial \mathrm{y}} \frac{\partial \mathrm{u}}{\partial \mathrm{p}}\right]
$$

onde g é a aceleração da gravidade, $\zeta_{p}$ é a componente vertical da vorticidade relativa em coordenada isobárica e $\theta$ é a temperatura potencial. Cada Unidade de Vorticidade Potencial (1 UVP) corresponde a $10^{-6} \mathrm{~m}^{2} \mathrm{~s}^{-1} \mathrm{~K} \mathrm{~kg}^{-1}$. Ressalta-se que no Hemisfério Sul os valores da UVP são tipicamente negativos, pois estão associados à vorticidade ciclônica.

\section{RESULTADOS}

\subsection{Condições de Tempo Associadas ao Ciclone}

O ciclone da primeira semana de maio de 2008 causou taxas elevadas de precipitação, principalmente da fronteira leste de Santa Catarina (SC) e Rio Grande do Sul (RS) até o município de Porto Alegre no RS (Figura 1b). Em São Joaquim (SC), a precipitação durante a atuação do sistema correspondeu a $90 \%$ do total climatológico esperado para o mês, enquanto em Torres e Porto Alegre (RS) a precipitação excedeu em mais de $65 \%$ a climatologia mensal (Figura $1 \mathrm{~b}$ ). Estes totais elevados de precipitação registrados num curto período ( $\sim 3$ dias) são característicos de eventos severos. Portanto, é de grande importância compreender a dinâmica de desenvolvimento e a evolução sinótica deste evento, buscando com isto auxiliar previsores do tempo no reconhecimento de eventos futuros similares, bem como auxiliar na interpretação de resultados de previsões numéricas de tempo.

O ciclone também provocou ventos fortes ao longo de todo o litoral sul e sudeste do Brasil entre os dias 02 e 06 de maio (Figura 2). Os ventos mais intensos foram registrados no dia 03 , quando no leste do RS e SC atingiram intensidade de $\sim 34$ $\mathrm{ms}^{-1}$ (Figura $2 \mathrm{~b}$ ). No dia $04, \mathrm{o}$ escoamento próximo à superfície mostra forte giro ciclônico, com o sistema centrado entre $29^{\circ} \mathrm{S}$ e $48^{\circ} \mathrm{W}$, com ventos de sudeste de até $\sim 20 \mathrm{~m} \mathrm{~s}^{-1}$ dirigidos para o RS e SC (Figura 2c). Já no dia 06, os ventos sopram de sudoeste nesta região (Figura 2d), uma vez que o ciclone se deslocou para

\begin{tabular}{|c|c|c|c|c|}
\hline \multirow{2}{*}{ Termo } & \multicolumn{2}{|c|}{ Favorável a Ciclogênese } & \multicolumn{2}{|c|}{ Desfavorável a Ciclogênese } \\
\hline & ANÁLISE & $\tilde{\mathrm{N}}^{2}(T E R M O)$ & ANÁLISE & $\tilde{\mathrm{N}}^{2}($ TERMO $)$ \\
\hline 1A: Tendênciada Vorticidade Absoluta em $1000 \mathrm{hPa}$ & $<0$ & & $>0$ & \\
\hline 1B:Advecção de Vorticidade Absoluta em $500 \mathrm{hPa}$ & $<0$ & & $>0$ & \\
\hline $\begin{array}{l}\text { 1C:Advecção de espessura na camada entre } 1000 \text { e } 500 \\
h \mathrm{hPa}\end{array}$ & $>0$ & $<0$ & $<0$ & $>0$ \\
\hline 1D: Termos de Estabilidade (Adiabático) & $>0$ & $<0$ & $<0$ & $>0$ \\
\hline $\begin{array}{l}\text { 1E: Taxa de aquecimento médio da camada entre } \\
\qquad 1000 \text { e } 500 \mathrm{hPa} \text { (Diabático) }\end{array}$ & $>0$ & $<0$ & $<0$ & $>0$ \\
\hline
\end{tabular}
o oceano Atlântico (Figuras 1a e 2d).

Tabela 1 - Avaliação dos termos da equação do desenvolvimento de Sutcliffe para o Hemisfério Sul: de forma isolada (coluna ANÁLISE) e inseridos na equação (coluna $\nabla^{2}($ TERMO)). 


\subsection{Análise Sinótica}

\section{a) Pré-ciclogênese}

$\mathrm{Na}$ imagem de satélite no canal infravermelho às 0000 UTC do dia $1^{\circ}$ de maio, há pouca nebulosidade no nordeste da Argentina (Figura 3a). O campo de altura geopotencial em
$500 \mathrm{hPa}$ (Figura 3b) exibe um cavado, praticamente fechado, alinhado noroeste-sudeste sobre o norte do Chile e noroeste da Argentina $\left(30^{\circ} \mathrm{S}\right.$ e $\left.70^{\circ} \mathrm{W}\right)$. A leste do cavado tem-se advecção de vorticidade absoluta ciclônica de até $-16 \times 10^{-10} \mathrm{~s}^{-2}$. Já em superfície, exatamente abaixo da crista em $500 \mathrm{hPa}$ (com eixo desde MT até RS), nota-se um cavado invertido na pressão ao nível médio do mar (PNMM), entre $20^{\circ} \mathrm{S}$ e $30^{\circ} \mathrm{S}$, centrado

a)

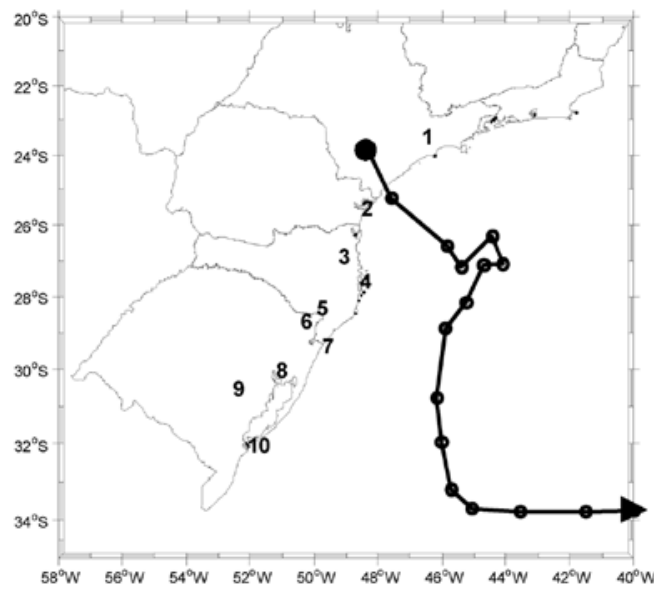

b)
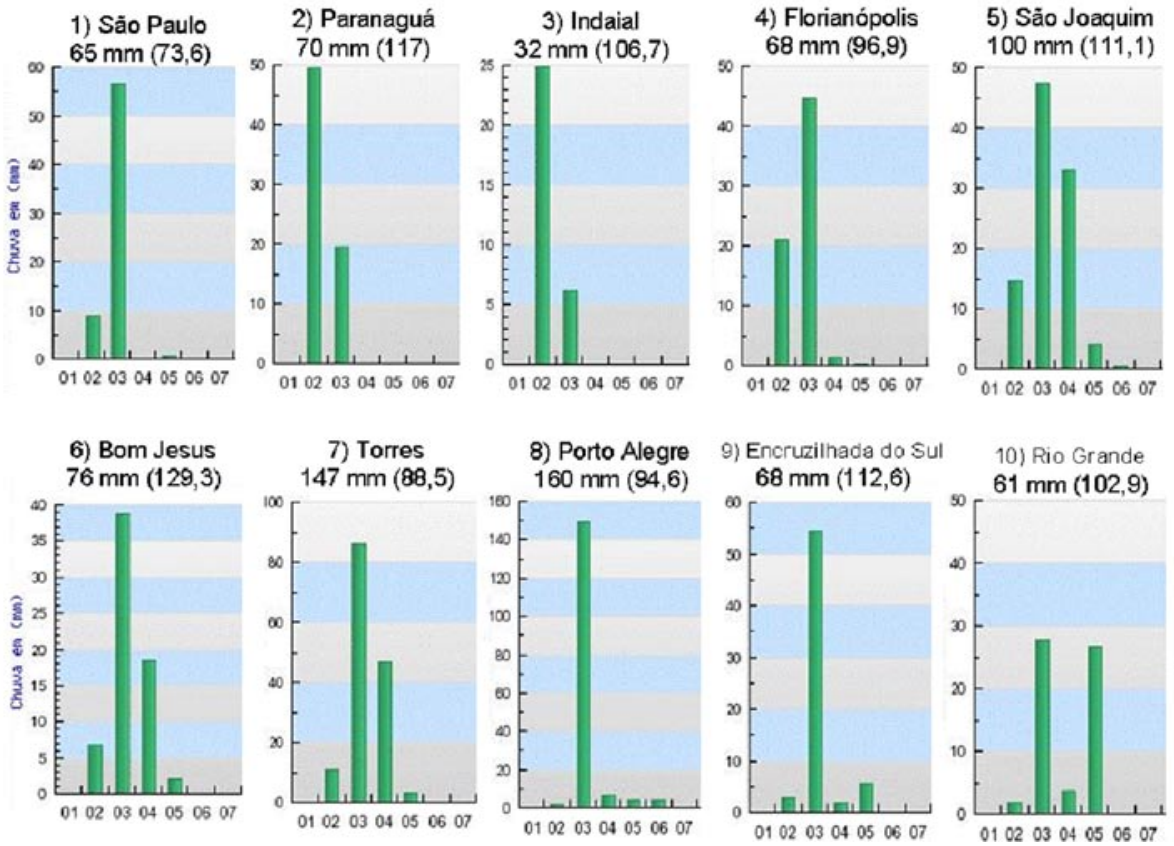

Figura 1 - (a) Trajetória do ciclone, com posição indicada a cada 6 h, entre 1800 UTC do dia 02 de maio (indicada com um círculo preenchido) até 1200 UTC do dia 06 de maio (indicada com uma seta) baseada em informações de PNMM. A figura também apresenta a localização de 10 estações meteorológicas ao longo da costa sul/sudeste do Brasil (números de 1 a 10); (b) precipitação (mm) acumulada em 24 h para as estações meteorológicas (1 a 10). No topo dos gráficos da Figura b são indicados a chuva total entre os dias 01 e 07 de maio e o valor climatológico para o mês de maio (climatologia do período 1961 a 1990, valores entre parênteses). Essas informações foram obtidas em www.inmet.gov.br, exceto a climatologia da estação meteorológica de Rio Grande que foi obtida de Reboita (2001). 
na longitude de $55^{\circ} \mathrm{W}$ (Figura 3c). Este cavado invertido em superfície pode ser uma resposta à advecção de vorticidade absoluta ciclônica em $500 \mathrm{hPa}$ (Figura 3b), que tende a produzir vorticidade ciclônica em baixos níveis (Equação 1), e também contribui para movimento vertical ascendente, explicando, assim, a presença de nebulosidade no nordeste da Argentina (Figura 3a), mesmo com convergência do fluxo de umidade muito pequena, tanto em $850 \mathrm{hPa}$ (Figura 3c) como a integrada na vertical (figura não apresentada).

Às 0000 UTC do dia 02 de maio, a nebulosidade aumenta e cobre toda a região sul do Brasil (Figura 3d). Em níveis médios, o cavado desloca-se para leste, em relação às 0000 UTC do dia $1^{\circ}$ de maio, e nota-se o fechamento de uma isolinha de altura geopotencial, caracterizando a formação de um VCAN (Figura 3e). A formação do VCAN pode ter alguma contribuição dos Andes, pois comparando as Figuras $3 \mathrm{~b}$ e $3 \mathrm{e}$ nota-se a intensificação do cavado, com a formação do VCAN, após cruzar as montanhas que nesta latitude atingem alturas de 2500-3000 m. No leste do VCAN, em superfície, surge uma circulação ciclônica de $-1,0 \times 10^{-5} \mathrm{~s}^{-1}$ sobre o Paraguai, nordeste da Argentina e oeste da região sul do Brasil (figura não mostrada), que representa o primeiro indício do ciclone em estudo. Entretanto, na PNMM as isóbaras ainda não estão fechadas, e observa-se apenas um cavado invertido $\left(\sim 25^{\circ} \mathrm{S}\right.$ e $\left.55^{\circ} \mathrm{W}\right)$, acompanhado por cristas invertidas a leste e a oeste (Figura 3f). A PNMM só mostra isóbaras fechadas às 1800 UTC
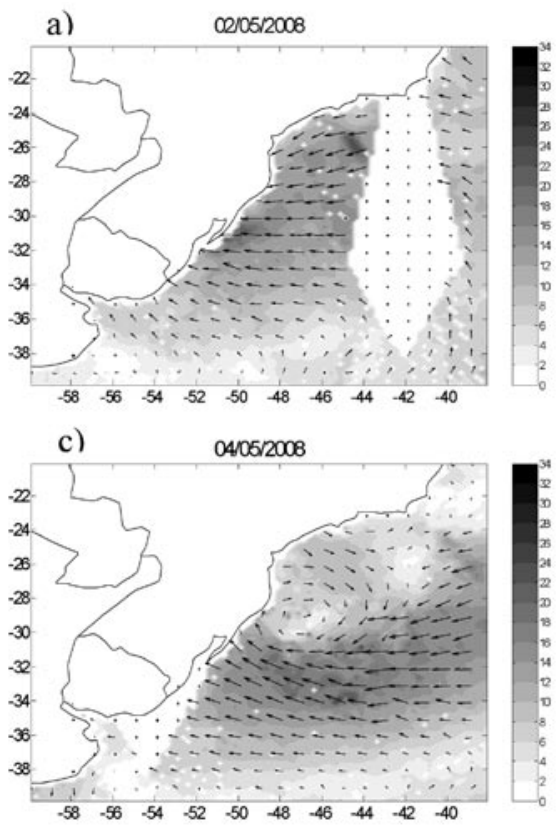

$\leftarrow 10 \mathrm{~ms}^{-1}$ do dia 02 de maio entre as costas do sul e sudeste do Brasil (figura não apresentada). Ao sul do cavado invertido em superfície temse um centro de alta pressão com 1026 hPa (Figura 3f). Caso semelhante foi estudado por Gan (1992) e Gan e Rao (1996).

\section{b) Ciclogênese}

Neste estudo, a ciclogênese foi considerada no horário em que apareceram isóbaras fechadas no campo de PNMM, o que ocorreu às 1800 UTC do dia 02 de maio. No entanto, será analisado o horário das 0000 UTC do dia 03 , quando o ciclone em superfície já é bastante evidente na PNMM.

A imagem de satélite das 0000 UTC do dia 03 de maio mostra um aglomerado de nuvens, com estrutura bastante circular, sobre a costa do RS, e outra banda de muita nebulosidade orientada noroeste-sudeste desde o sudeste do Brasil até o Oceano Atlântico (Figura 4a). Em 500 hPa, entre $20^{\circ}$ e $40^{\circ} \mathrm{S}$, se estabelece um padrão de bloqueio do tipo dipolo (Rex 1950 a,b), caracterizado pela incursão no seu setor sul de uma crista a sudoeste do cavado e do VCAN (Figura 4b). A advecção de vorticidade absoluta em $500 \mathrm{hPa}$, atinge seu valor máximo desde o dia $1^{\circ}$ de maio chegando a $-20 \times 10^{-10}$ $\mathrm{s}^{-2}$ (Figura 4b), devido ao aumento do gradiente de vorticidade absoluta no setor leste do cavado (figura não mostrada). Em superfície, entre as costas das regiões sul e sudeste do Brasil, o ciclone possui pressão central de $1012 \mathrm{hPa}$ (Figura 4c). Ao
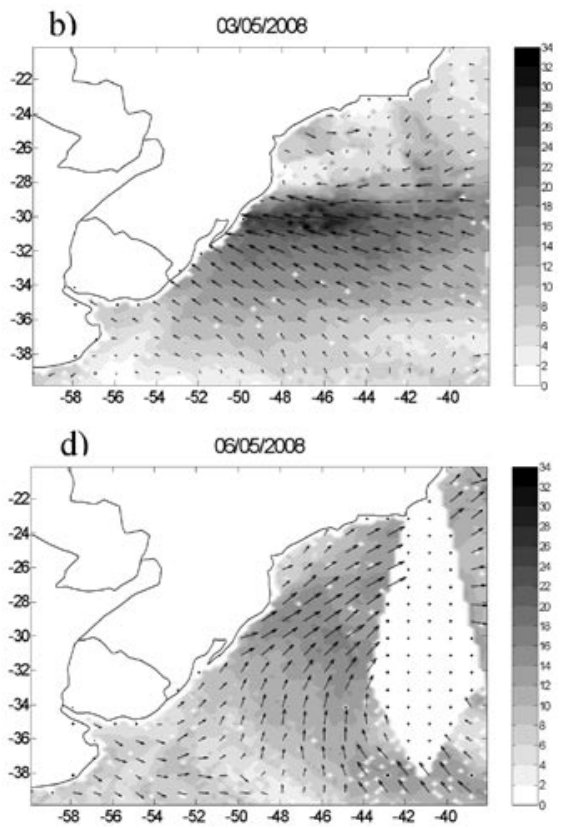

Figura 2 - Média diária da intensidade ( $\mathrm{m} \mathrm{s}^{-1}$ sombreado) e direção do vento (setas) nos dias 02, 03, 04 e 06 de maio de 2008 obtida do QuikSCAT. Em (a) e (d) o QuikSCAT não registrou dados nas longitudes entre $40^{\circ}$ a $44^{\circ} \mathrm{W}$. 
sul deste sistema, o anticiclone ganha intensidade, chegando a $1030 \mathrm{hPa}$, mas em relação aos horários anteriores (Figura 3cf) praticamente não sofreu deslocamento, ou seja, permaneceu semi-estacionário.

\section{C) Pós-ciclogênese}

Entre 0600 UTC do dia 03 (figura não apresentada) e 0000 UTC do dia 04 de maio, o bloqueio em níveis médios se intensifica e permanece estacionário próximo à costa leste da América do Sul (Figura 5b). A partir das 0000 UTC do dia 05 (Figura 5e) o bloqueio enfraquece, mas novamente ganha intensidade no oceano Atlântico, já longe da costa (próximo de $45^{\circ} \mathrm{S}$ e $50^{\circ} \mathrm{W}$ ), às $0000 \mathrm{UTC}$ do dia 06 de maio (Figura $5 \mathrm{~h}$ ).

Em superfície, o ciclone mantém-se confinado próximo à costa brasileira desde o dia 03 até o dia 06 de maio às 0000 UTC (Figuras 5 c-f-i). De acordo com Sutcliffe, o deslocamento dos sistemas de baixa pressão é controlado pela advecção de vorticidade absoluta ciclônica na média troposfera. Entretanto, a advecção de ar quente na coluna também exerce um papel importante, uma vez que gera tendência de vorticidade ciclônica de acordo com a Equação 1, alterando assim os gradientes de vorticidade e, portanto, a própria advecção de vorticidade (Carlson, 1991). Além disso, está implícito na equação de Sutcliffe (Equação 1) que o sistema não é carregado pelo escoamento, mas que o campo de pressão é reconstruído continuamente pelo campo de divergência. Assim, no evento em estudo, a presença da alta pressão em superfície nos setores sul e leste do ciclone (Figuras 4c, $5 \mathrm{c}$ e $5 \mathrm{f}$ ) desfavorece a convergência de massa e, então, o deslocamento do sistema. Além disso, a Figura 9 indica que os núcleos de máxima advecção de vorticidade absoluta em $500 \mathrm{hPa}$ também tiveram movimento lento após o dia 03 de maio, contribuindo também para explicar a baixa velocidade de deslocamento do ciclone em superfície. Outro mecanismo importante é a junção do giro do vento da alta e da baixa que propicia advecção de ar quente no sul do ciclone (como será mostrado na seção 3.3), o que inibe a propagação para leste e favorece o deslocamento para sul.

O ciclone situa-se às 0000 UTC do dia 03 (Figura 3c) entre as costas das regiões sul e sudeste do Brasil e entre os dias 03 e 04 apresenta deslocamento para sudeste, tal que às 0000 UTC do dia 04 encontra-se próximo à costa dos estados
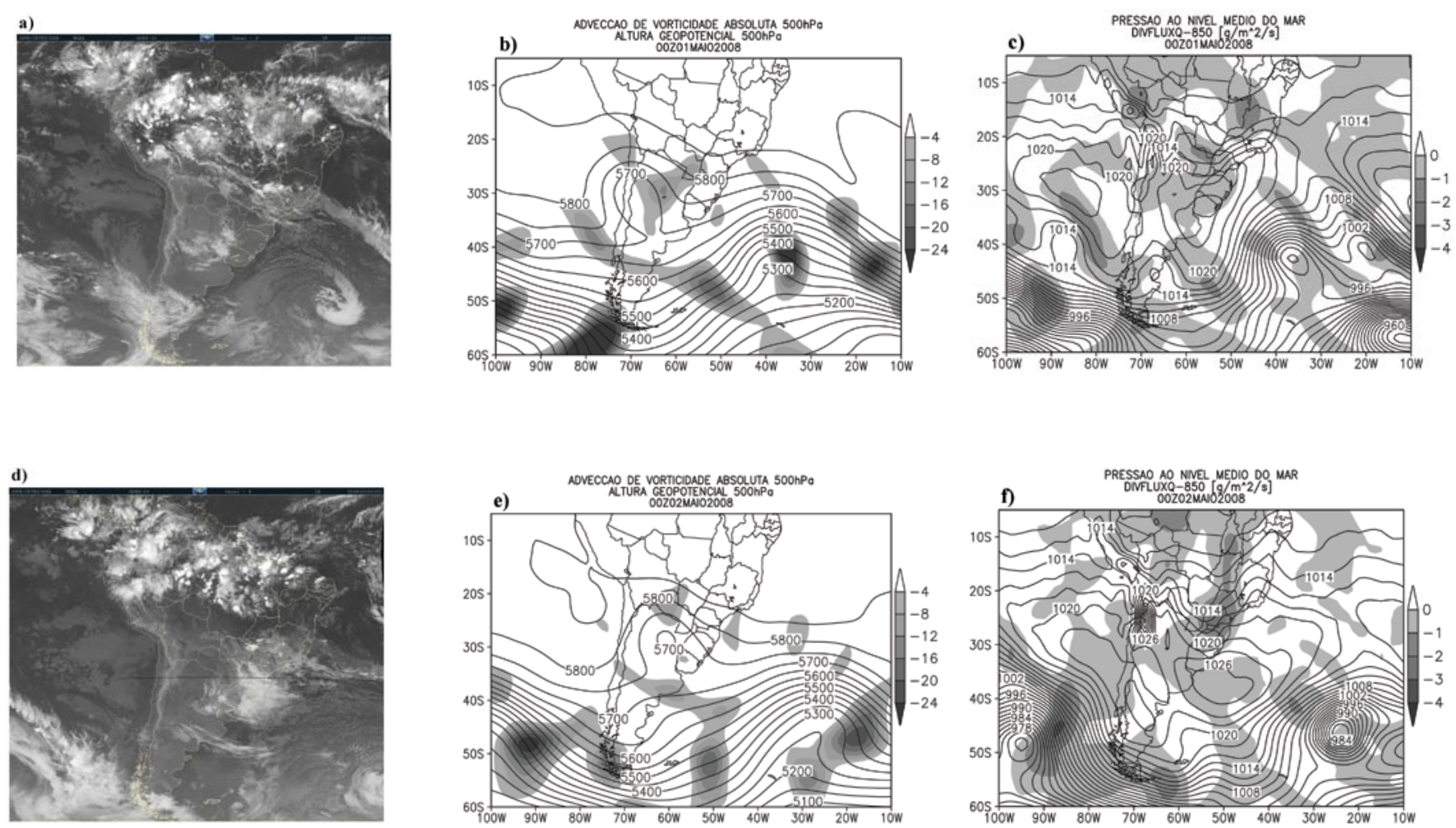

Figura3-Pré-ciclogênese:(aed)imagem do satéliteGOES-10 nocanal infravermelho; (bee)advecçãodevorticidadeabsolutaem $500 \mathrm{hPa}\left(10^{-10} \mathrm{~s}^{-2}\right)($ sombreado) e altura geopotencial em $500 \mathrm{hPa}(\mathrm{m})$ (linhas sólidas); (c e f) pressão atmosférica ao nível médio do mar (hPa) (linhas sólidas) e divergência do fluxo de umidade em $850 \mathrm{hPa}\left(10^{-4} \mathrm{~g} \mathrm{~kg}^{-1} \mathrm{~s}^{-1}\right)$ (sombreado) nos dias $1^{\circ} \mathrm{e} 2$ de maio de 2008 às 0000 UTC. Painel superior corresponde ao dia $1^{\circ} \mathrm{e} o$ inferior ao dia 02 de maio. 

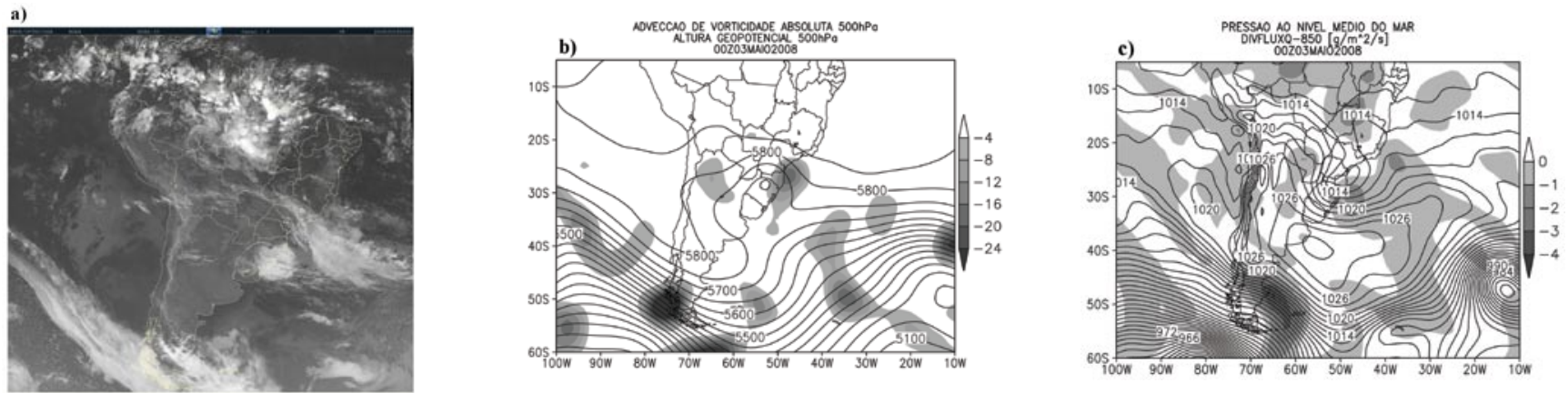

Figura 4 - Similar à Figura 3, mas para a formação do ciclone com base no campo da pressão ao nível médio do mar no dia 03 de maio de 2008 às 0000 UTC.
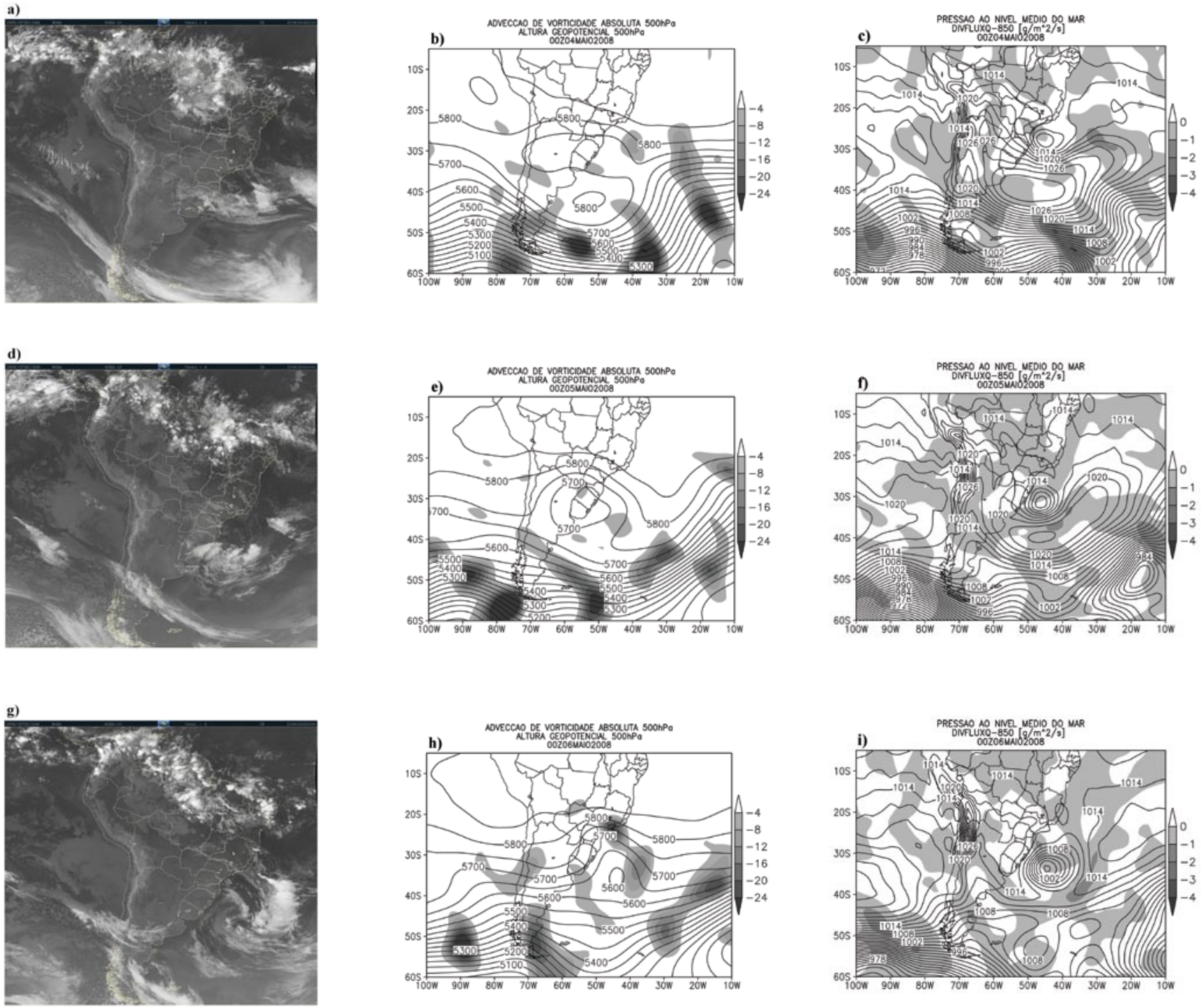

Figura 5 - Similar à Figura 3, mas para o período pós-ciclogênese. Painel superior corresponde ao dia 04 (a-c), central ao dia 05 (d-f) e inferior ao dia 06 de maio (g-i) às 0000 UTC. 
do Paraná e SC (Figura 1a). O deslocamento do ciclone para sul após o dia 04 faz com que às 0000 UTC do dia 05 atinja a costa do Rio Grande do Sul (Figura 1a). A partir deste horário, o ciclone em superfície sofre uma intensificação em termos de pressão central e tanto o anticiclone em superfície como a crista em $500 \mathrm{hPa}$ enfraquecem (Figuras $5 \mathrm{c}$-f-i). Às 0000 UTC do dia 06, o ciclone atinge pressão central de $999 \mathrm{hPa}$ (Figura 5i) e, a partir deste horário, afasta-se do continente diminuindo sua ação sobre as regiões sul e sudeste do Brasil (Figura 1a). Comparando a Figura 9 e a 1a, nota-se que o deslocamento do ciclone em superfície segue aproximadamente o deslocamento do núcleo de máxima advecção de vorticidade ciclônica em $500 \mathrm{hPa}$.

\subsection{Análise dos Termos da Equação de Sutcliffe}

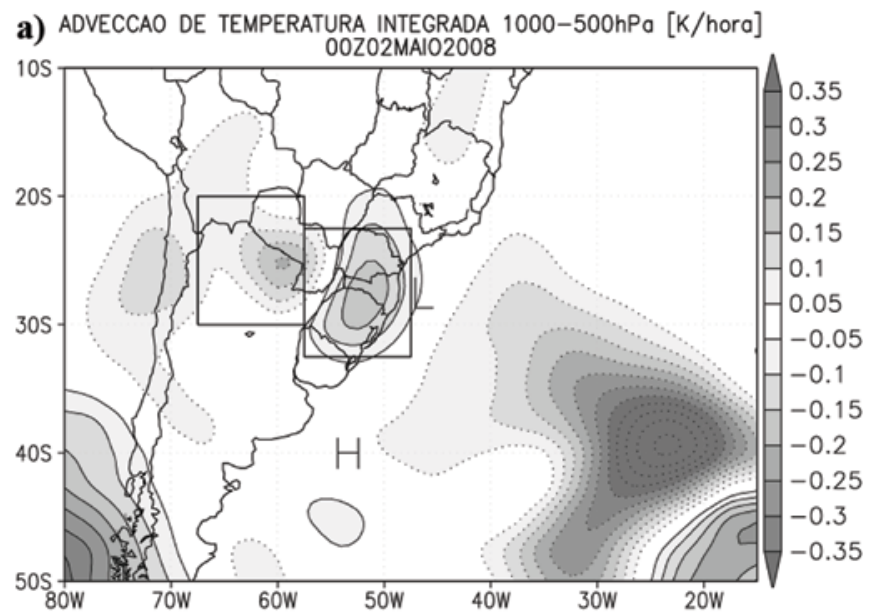

Esta seção analisa a contribuição de cada termo da equação do desenvolvimento de Sutcliffe (Equação 1) na formação do ciclone.

Às 0000 UTC do dia 02 de maio a advecção de vorticidade absoluta ciclônica em $500 \mathrm{hPa}$ é fraca (até $-12 \mathrm{x}$ $10^{-10} \mathrm{~s}^{-1}$ ) sobre o centro-norte do Paraguai, ou seja, a leste do cavado centrado em $65^{\circ} \mathrm{W}$ (Figura 3e). No setor centro-oeste deste cavado (norte-nordeste da Argentina e Paraguai) domina advecção de ar frio na camada entre $1000-500 \mathrm{hPa}$, enquanto advecção de ar quente é encontrada a leste (região sul do Brasil - Figura 6a). No setor norte da região de advecção de ar quente, os valores negativos do termo de estabilidade integrado entre 1000-500 hPa indicam resfriamento por expansão adiabática (Figura 7a). Segundo a equação de Sutcliffe, movimentos

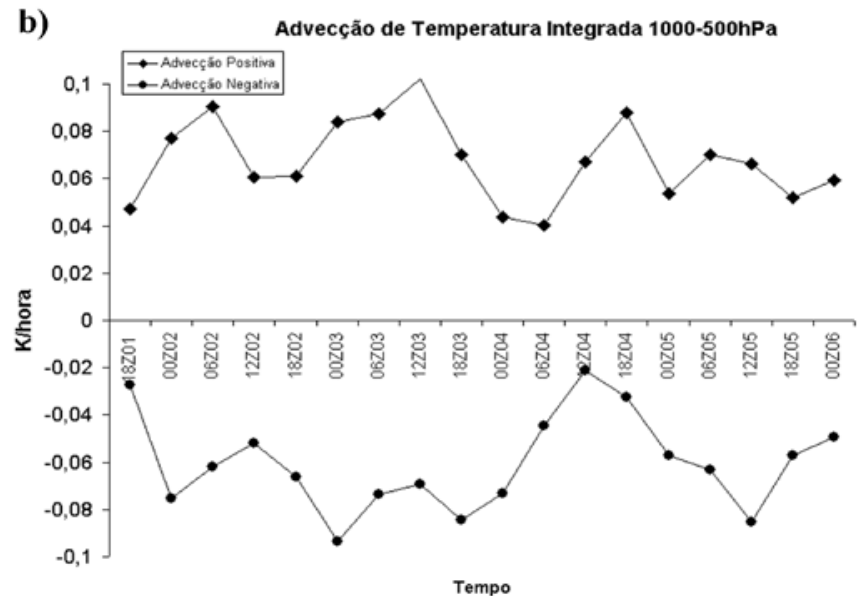

Figura 6 - Advecção horizontal de temperatura integrada entre 1000 e $500 \mathrm{hPa}$ (linha sólida indica advecção quente e linha pontilhada advecção fria): a) distribuição espacial às 0000 UTC do dia 02 de maio de 2008 e b) média em áreas de $10^{\circ} \times 10^{\circ}$ no setor de advecção quente e fria acompanhando o movimento do ciclone com o tempo. Um exemplo da posição das áreas é dado na figura a), nesta figura H representa a localização do sistema de alta pressão na superfície.
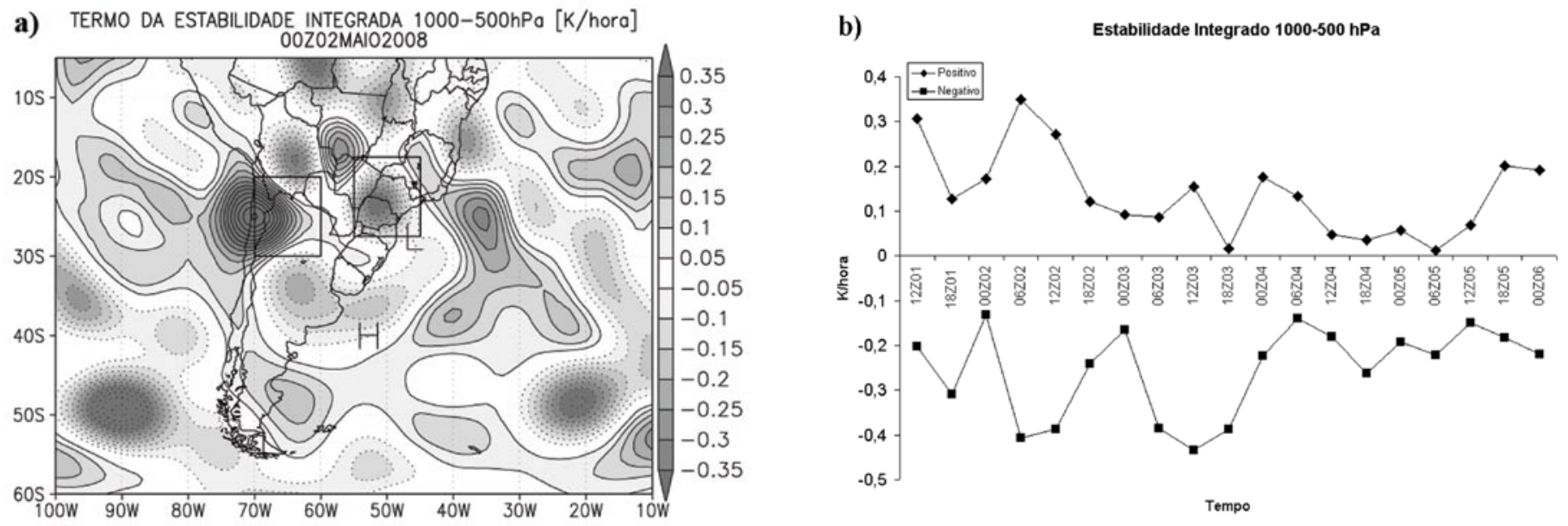

Figura 7 - Similar à Figura 6, mas para o termo de estabilidade integrado entre 1000 e $500 \mathrm{hPa}$. 
verticais ascendentes desfavorecem ciclogênese, pois o ar que resfria por expansão adiabática torna a coluna atmosférica mais pesada impedindo o abaixamento da pressão em superfície. Por outro lado, para ocorrer ciclogênese são necessários movimentos ascendentes (Sutcliffe, 1947; Kousky e Elias, 1982) o que implica, em geral, em termo de estabilidade negativo na região de advecção de ar quente, portanto, este termo atua como um freio para a intensificação do sistema. $\mathrm{O}$ termo diabático, integrado entre 1000-500 hPa (Figura 8a), mostra aquecimento na camada atmosférica sobre Paraná e São Paulo no mesmo local onde há intensa convergência do fluxo de umidade integrado na coluna (figura não apresentada) e advecção de ar quente (Figura 6a). O aquecimento diabático, provavelmente, deve-se à liberação de calor latente resultante do processo de condensação, já que a imagem do infravermelho indica nebulosidade nesta área (Figura 3d). Ao sul do aquecimento diabático encontra-se uma área de resfriamento (Figura 8a).

Na seção 3.2 foi mencionado que o campo de vorticidade relativa próximo à superfície, já indicava vorticidade ciclônica sobre o oeste do sul do Brasil, representando a formação de um ciclone às 0000 UTC do dia 02 , enquanto no campo de pressão o ciclone só se tornou aparente 18 horas depois no sudeste do Brasil. As análises apresentadas até aqui indicam que o desenvolvimento deste sistema (às 0000 UTC) foi possível pela presença de um cavado em $500 \mathrm{hPa}$, onde no seu setor leste existia advecção de ar quente na camada 1000-500hPa e convergência de fluxo de umidade em baixos níveis. A advecção de ar quente (integrada na coluna - Figura 6a) somada ao aquecimento diabático (Figura 8a), resultante da liberação de calor latente, que é decorrente da convergência do fluxo de umidade na região (Figura $3 \mathrm{c}-\mathrm{f}$ ), tornam a camada atmosférica mais leve, com conseqüente queda de pressão em baixos níveis. A presença de movimento vertical ascendente acima do sistema em superfície (oeste da região sul do Brasil) é confirmada

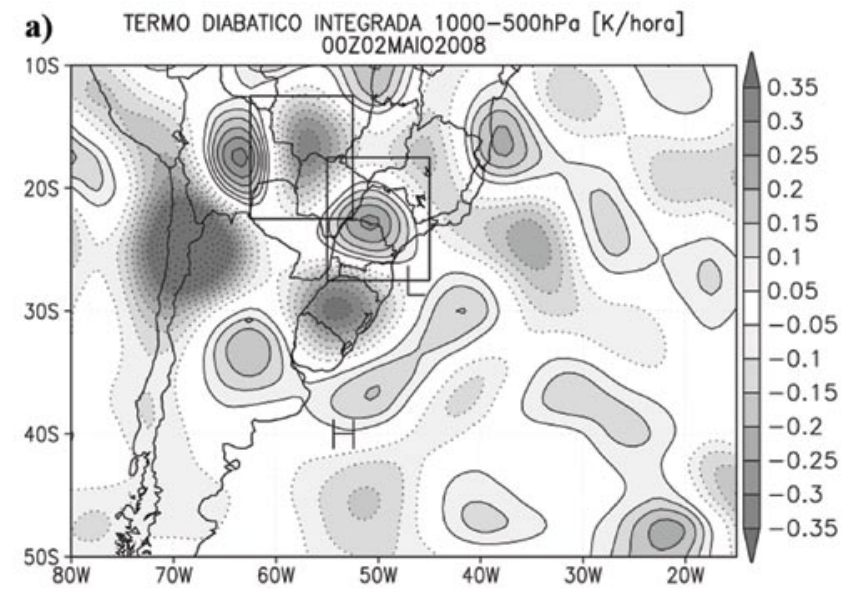

pelo termo de estabilidade (Figura 7a) da equação de Sutcliffe (Equação 1), que por ser negativo se contrapõe à ciclogênese. Às 0000 UTC do dia 02 não é registrada advecção de vorticidade absoluta em $500 \mathrm{hPa}$ nas proximidades da área de ciclogênese, mas sim a oeste desta, porém nos horários posteriores também contribuiu para aumento da vorticidade ciclônica em superfície e deslocamento do ciclone (Figura 9).

Às 0000 UTC do dia 03, a advecção de vorticidade absoluta ciclônica em $500 \mathrm{hPa}$ (Figura 4b) e a advecção de temperatura positiva na camada entre $1000-500 \mathrm{hPa}$ (figura não apresentada) contribuem para a organização do ciclone em superfície entre as costas sul e sudeste do Brasil. Nos horários seguintes (até às 0000 UTC do dia 05), o giro anticiclônico da alta, juntamente com o giro ciclônico do sistema, geram um escoamento de nordeste que aumenta o transporte de ar quente de latitudes mais baixas para o setor sul do ciclone, o que contribui para intensificar a advecção quente na camada entre 1000-500 hPa. Isto favorece a queda de pressão e a intensificação da vorticidade ciclônica em baixos níveis (Equação 1), portanto, contribui para o deslocamento do ciclone para sul, mas o anticiclone situado ao sul do sistema dificulta seu deslocamento, reduzindo sua velocidade de deslocamento para cerca de $5 \mathrm{~m}$ $\mathrm{s}^{-1}$, que está abaixo do valor climatológico de $9 \mathrm{~m} \mathrm{~s}^{-1}$ (Reboita, 2008). Até às 1800 UTC do dia 05 de maio, as regiões positivas e negativas dos termos da equação de Sutcliffe tiveram padrão similar (figuras não apresentadas), isto é, advecção de ar quente ao sul/sudoeste do ciclone, advecção fria no norte/noroeste, advecção de vorticidade absoluta ciclônica a leste/sudeste, que foram acompanhadas, respectivamente, por valores negativos (positivos) e positivos (negativos) do termo de estabilidade (do termo de aquecimento diabático). Devido à similaridade na distribuição espacial de cada termo da equação ao longo do tempo, calculou-se a evolução temporal da média de tais termos numa área de $10^{\circ}$ de latitude por $10^{\circ}$ de longitude, que

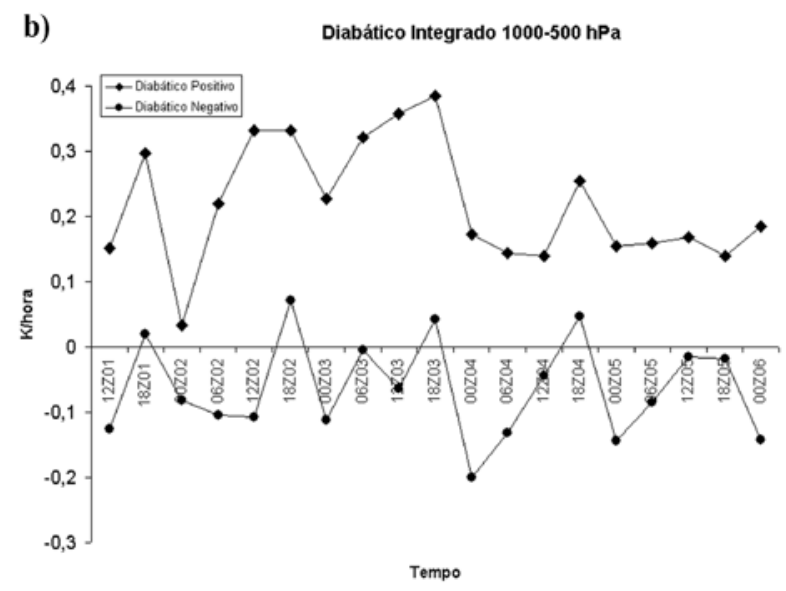

Figura 8 - Similar à Figura 6, mas para o termo diabático integrado entre 1000 e $500 \mathrm{hPa}$. 
foram centradas nos máximos e mínimos nas proximidades do ciclone em superfície, cuja evolução temporal está nas Figuras $6 b, 7 b$ e $8 b$. Os máximos e mínimos da advecção de temperatura apresentaram uma simetria ao longo da trajetória do sistema com valores médios na área não ultrapassando $0,1 \mathrm{~K} \mathrm{hora}^{-1}$ entre os dias 02 e 06 às 0000 UTC (Figura 6b). Após 0000 UTC do dia 06 de maio, o anticiclone que circundava o ciclone enfraquece (Figura 5i), e o ciclone dirige-se para o Atlântico central numa trajetória praticamente zonal (Figura 1a).

A evolução temporal do termo da estabilidade integrado entre 1000-500 hPa mostra que valores negativos, associados com movimento vertical ascendente no ciclone, são maiores inicialmente (Figura 7b), e a partir do dia 04, tanto os valores negativos como os positivos enfraquecem. $\mathrm{O}$ termo diabático apresenta comportamento similar, i.e., inicialmente o aquecimento da atmosfera é intenso e diminui sensivelmente a partir do dia 04 de maio (Figura 8b). Nota-se máximo aquecimento diabático nos dias 02 e 03, quando as nuvens são mais profundas, como mostram as imagens de satélite no canal infravermelho (Figuras $3 \mathrm{~d}$ e $4 \mathrm{a}$ ). Como indica o termo de estabilidade, neste período os movimentos verticais ascendentes também são mais intensos, com conseqüente maior resfriamento adiabático (Figura. 7b).

A permanência do ciclone ao longo da costa brasileira esteve associada à presença do anticiclone quase estacionário em superfície no setor sul/leste do ciclone (exemplo Figura 3f) que, por sua vez, foi intensificado pelo bloqueio atmosférico em $500 \mathrm{hPa}$ (Figura 3e). Tal bloqueio atmosférico é objeto de estudo da próxima seção.

\subsection{Bloqueio Atmosférico}

A seção 3.2 mostrou que o desenvolvimento do ciclone em superfície esteve associado a um VCAN (ou baixa desprendida) em $500 \mathrm{hPa}$. O estabelecimento do VCAN e o posicionamento de uma crista ao sul deste deram origem a um padrão de bloqueio no escoamento atmosférico, que contribuiu para o lento deslocamento do ciclone em superfície. Portanto, esta seção aborda os mecanismos que favoreceram a ocorrência e o lento deslocamento do VCAN em $500 \mathrm{hPa}$, sistema integrante do bloqueio atmosférico do tipo dipolo que influenciou os sistemas em superfície.

Às 0000 UTC do dia $1^{\circ}$ de maio, entre o oceano Pacífico e o oeste da América do Sul, o cavado no campo do geopotencial em $500 \mathrm{hPa}$ é acompanhado de anomalia de VP em $300 \mathrm{hPa}$ (figura não mostrada) e, ao sul do cavado, há uma crista sobre o extremo sul da América do Sul (Figura 3b). Às 1200 UTC deste mesmo dia (figura não mostrada), na região da anomalia de VP, as isolinhas de geopotencial se fecham, originando o VCAN. Em altos níveis, as anomalias de VP estão relacionadas à incursão de ar mais estável da estratosfera para os níveis mais baixos, isto é, para a média e alta troposfera (Hoskins et al., 1985; Bluestein, 1993). Em movimentos sem fricção e adiabáticos, o ar estratosférico com alta estabilidade estática, ao entrar em

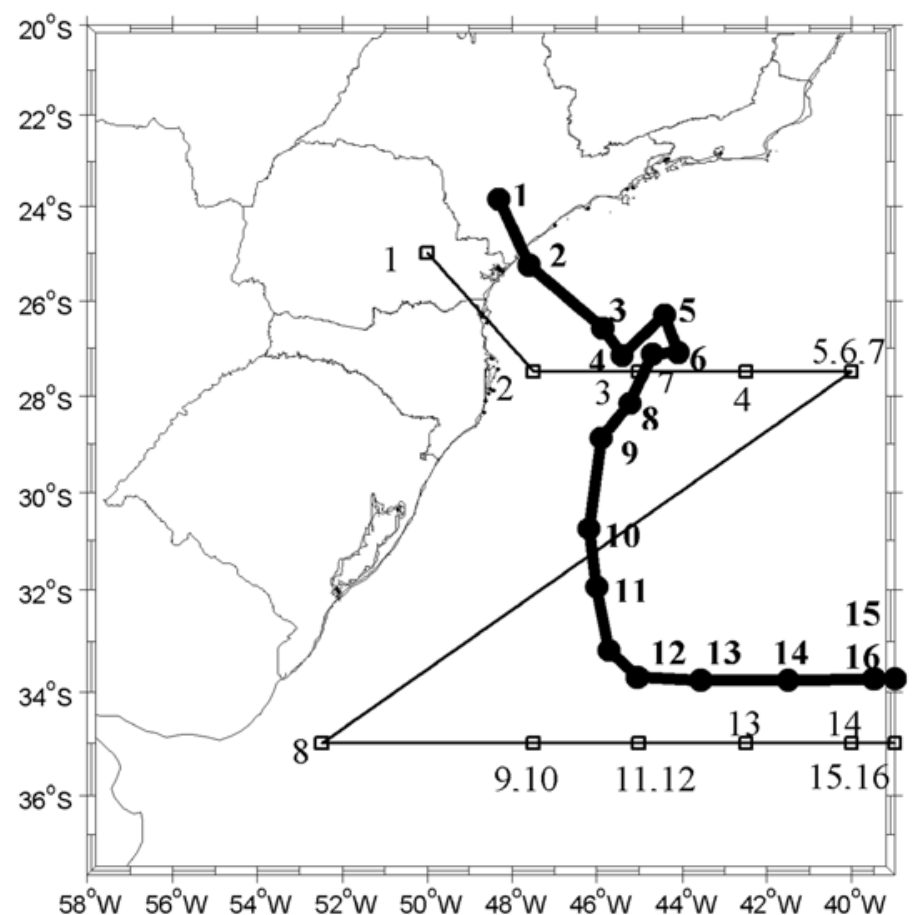

Figura 9 - Trajetória do ciclone (linha preta grossa) e dos centros de máxima advecção de vorticidade absoluta ciclônica em 500 hPa (linha preta fina) a cada 6 h desde 02 de maio às 1800 UTC até 06 de maio às 1200 UTC. 
um ambiente menos estável, adquire vorticidade ciclônica por conservação de VP (Hoskins et al., 1985; Bluestein, 1993). A vorticidade ciclônica contribui para a formação de circulações fechadas na alta e média troposfera, podendo ou não se estender até a superfície.

Às 1200 UTC do dia 02 de maio, a anomalia de VP em $300 \mathrm{hPa}$ (Figura 10a) é acompanhada por intensa vorticidade ciclônica, com valores atingindo $-15 \times 10^{-5} \mathrm{~s}^{-1}$, se estendendo até baixos níveis $(\sim 900 \mathrm{hPa})$, como mostra a Figura 11. Esta anomalia de VP, associada ao VCAN, desloca-se para leste e, às 1800 UTC do dia 02, atinge os estados do RS, SC e sul do Paraguai (figura não apresentada). Após 18 horas, às 1200 UTC do dia 03 de maio, observam-se dois núcleos de VP em $300 \mathrm{hPa}$, um sobre o norte da Argentina e outro sobre SC e Paraná, ou seja, praticamente sobre a baixa pressão em superfície (Figura 10b). $\mathrm{O}$ núcleo de VP sobre a Argentina contribui para o prolongamento

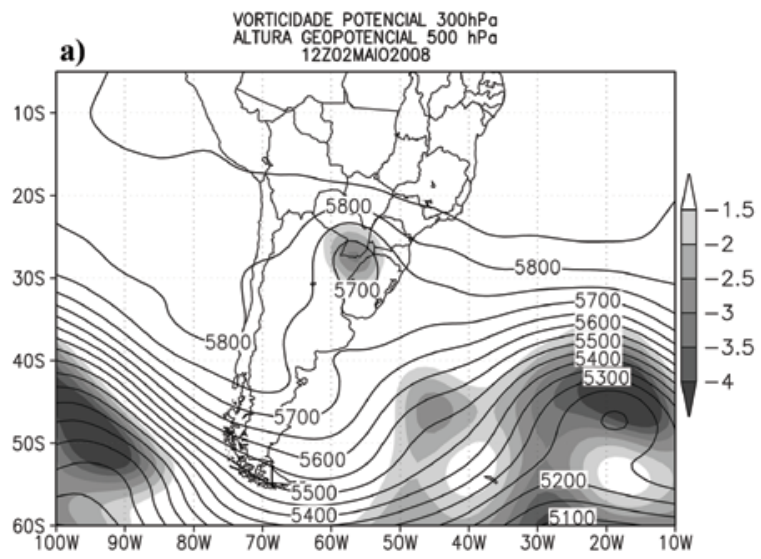

do cavado em $500 \mathrm{hPa}$ para noroeste, amplificando tanto o cavado como a crista.

O VCAN permanece estacionário por aproximadamente 4 dias, uma situação típica de bloqueio atmosférico do tipo dipolo (Rex, 1950 a-b), onde nas latitudes mais baixas, um centro frio de circulação ciclônica desprende-se do escoamento principal, e se encontra em fase com um centro quente de circulação anticiclônica nas latitudes mais altas. De acordo com Hoskins et al. (1985), o lento deslocamento do VCAN pode ser explicado pela intensidade da advecção de VP ciclônica a oeste da circulação ciclônica. No noroeste do VCAN, o vento de sul transporta VP ciclônica do pólo em direção ao equador, intensificando a advecção de VP ciclônica, enquanto no seu setor sudeste a advecção de VP ciclônica é fraca devido à menor advecção de VP ciclônica do equador para o pólo. Este padrão de advecção diminui drasticamente a velocidade de deslocamento

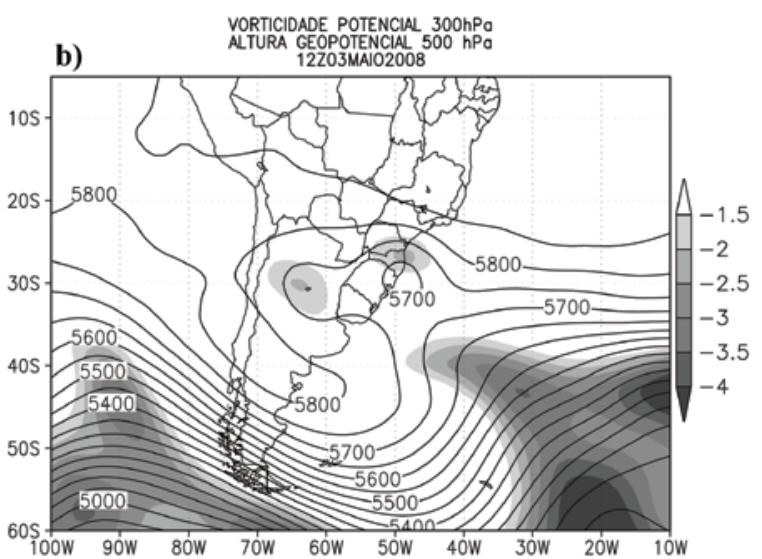

Figura 10 - Vorticidade potencial em $300 \mathrm{hPa}$ (sombreado em intervalos de 0,5 UVP) e altura geopotencial em $500 \mathrm{hPa}$ (linhas em intervalos de 50 m). a) 1200 UTC do dia 02 de maio e b) 1200 UTC do dia 03 de maio de 2008.

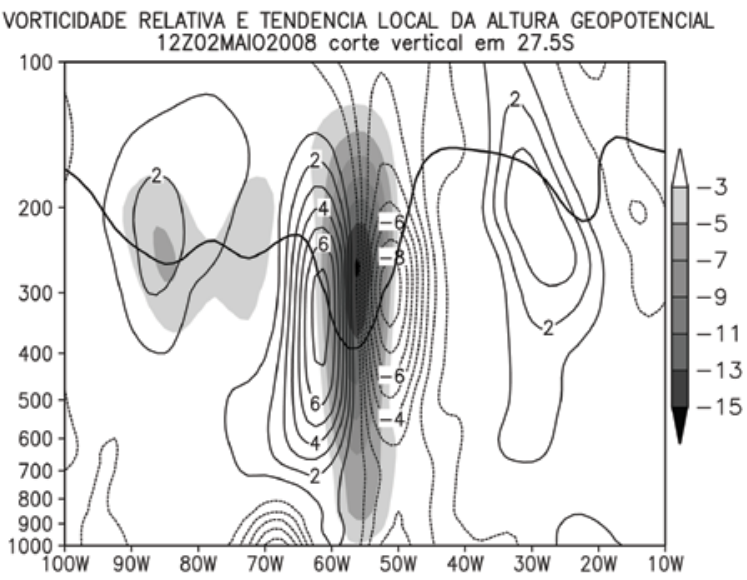

Figura 11 - Corte vertical em $27,5^{\circ} \mathrm{S}$ da vorticidade relativa (sombreado em intervalos de $2 \times 10^{-5} \mathrm{~s}^{-1}$ ) e tendência local da altura geopotencial (linhas sólidas indicam tendência positiva e pontilhadas tendência negativa em intervalos de $1 \mathrm{mh}^{-1}$ ) às $1200 \mathrm{UTC}$ do dia 03 de maio de 2008 . A linha sólida é o contorno de -1,5 UVP. 
do VCAN para leste. Com isso, como o deslocamento do sistema em superfície está associado ao de níveis médios/altos, sua velocidade de deslocamento também é afetada.

Entre as 1800 UTC do dia 03 e 0000 UTC do dia 05 , o ciclone em superfície desloca-se para sudoeste (Figura 1a), no mesmo período de máximo bloqueio (Figuras $4 \mathrm{~b}, 5 \mathrm{~b}$ e 5 e). Isto ocorre em função dos ventos anômalos de leste em altos níveis, gerados pela junção da circulação ciclônica ao norte com a anticiclônica ao sul do bloqueio do tipo dipolo, que contribuem em superfície para a advecção de ar quente a sudoeste do ciclone. Em 500 hPa, também há advecção de vorticidade ciclônica no sudoeste do ciclone (Figura 9), e ambos processos favorecem o deslocamento do ciclone para sudoeste. Segundo McTaggart-Cowan et al. (2006), o ciclone em superfície, que gerou o furacão Catarina, deslocou-se para oeste em direção às regiões de baixo cisalhamento vertical do vento por influência de ventos anômalos de leste. Estes ventos foram encontrados na junção da circulação ciclônica ao norte com a anticiclônica ao sul de um bloqueio do tipo dipolo. Embora o ciclone em estudo apresente características sinóticas similares às do furacão Catarina (bloqueio tipo dipolo, sistema de baixa pressão em superfície decorrente da influência de um VCAN, intenso aquecimento diabático permanecendo numa região de forte transferência de fluxos de calor latente e sensível do oceano para a atmosfera - figuras não apresentadas) seria necessário um estudo comparativo mais aprofundado, para entender porque o ciclone de maio não evoluiu para ciclone tropical como o Catarina, o que não constitui objetivo deste estudo. No entanto, vale ressaltar que o Catarina se desenvolveu sobre o oceano (porção centro-oeste do Atlântico Sul) e o ciclone de maio de 2008 muito próximo do continente, uma diferença importante entre os dois sistemas.

A partir da 0000 UTC do dia 06 (figura não apresentada), a intrusão de VP se enfraquece, o padrão dipolo de bloqueio se desfaz e a baixa pressão em superfície se desloca para leste, já com a alta pressão na retaguarda em superfície enfraquecida.

\section{CONCLUSÃO}

Na primeira semana de maio de 2008 , um ciclone atuou na costa da região sul do Brasil durante 4 dias, causando chuvas e ventos fortes nos estados do RS e SC, provocando muitos danos (quedas de árvores, enchentes e desabamentos). Algumas estações meteorológicas em apenas um ou dois dias, registraram chuvas acima da média climatológica mensal. Observações do QuikSCAT mostraram ventos soprando perpendiculares à costa do sul do Brasil por mais de 3 dias, e neste período atingiram velocidade acima de $30 \mathrm{~ms}^{-1}$.

Às 0000 UTC do dia 02 de maio, o campo de vorticidade relativa fornecia o primeiro indício do ciclone no oeste da região sul do Brasil, enquanto no campo de pressão o sistema só foi identificado 18 horas depois na costa do sudeste do Brasil. Isto mostra que a vorticidade relativa é mais adequada para identificação precoce dos sistemas meteorológicos, já que permite identificar tanto sistemas com isóbaras fechadas, quanto abertas, mas que já possuem rotação considerável, como também propôs Sinclair (1994).

A formação do ciclone foi avaliada através da equação do desenvolvimento de Sutcliffe. Esta análise mostrou, entre os principais mecanismos para a ciclogênese, a advecção de vorticidade absoluta ciclônica em $500 \mathrm{hPa}$ e a advecção de ar quente na coluna entre 1000 e $500 \mathrm{hPa}$, localizadas no setor leste de um cavado em $500 \mathrm{hPa}$, que se deslocava do Pacífico em direção ao Atlântico. Os processos diabáticos tiveram forte contribuição para a ciclogênese entre os dias 01 e 03 de maio e se contrapuseram ao resfriamento devido aos movimentos verticais ascendentes como medido pelo termo adiabático. Durante os quatro primeiros dias, o ciclone apresentou características distintas da climatologia, isto é, deslocamento predominante para sul e velocidade média de $5 \mathrm{~m} \mathrm{~s}^{-1}$, que é consideravelmente menor que os $9 \mathrm{~m} \mathrm{~s}^{-1}$ climatológico. O lento deslocamento foi associado à anomalia de $\mathrm{VP}$ em altos níveis que contribuiu para a formação de um VCAN, e este, por sua vez, constituiu o componente norte de um padrão de bloqueio do tipo dipolo na média troposfera. Tal bloqueio favoreceu a intensificação de uma alta pressão em superfície, que ocupava os setores sul e leste do ciclone, impedindo sua propagação zonal. Além disso, os posicionamentos do anticiciclone em superfície e do VCAN em níveis médios propiciaram, respectivamente, advecção de ar quente e de vorticidade ciclônica no setor sul do ciclone, o que também inibiu a propagação do ciclone para leste, favorecendo o deslocamento para sul. O ciclone em superfície só se afastou da costa sul do Brasil, quando o padrão de bloqueio em níveis médios se desconfigurou, à medida que a anomalia de vorticidade potencial enfraqueceu.

Este evento mostra que a vorticidade relativa em baixos níveis é uma das variáveis importantes para a detecção precoce de sistemas de baixa pressão. Além disso, o desenvolvimento do VCAN, associado ao padrão de bloqueio na média troposfera, pode indicar ciclones com lento deslocamento e, portanto, com grande potencial de atuação com chuvas e ventos fortes sobre uma mesma região por longo período de tempo.

\section{AGRADECIMENTOS}

Os autores agradecem ao National Center for Environmental Prediction, CPTEC/INPE e QUICKSCAT/NASA pela disponibilização dos dados utilizados neste estudo e ao suporte financeiro da CAPES (processo $\mathrm{N}^{0}$ BEX 0626/08-2) e CNPq (processos $\left.\mathrm{N}^{\circ} 476361 / 2006-0,150485 / 2009-3\right)$ ). O 
quarto autor também agradece ao CNPq e CAPES pelo suporte financeiro a esta pesquisa. Por fim, agrademos aos revisores anônimos pelas importantes sugestões.

\section{REFERÊNCIA BIBLIOGRÁFICAS}

BLUESTEIN, H. B. Synoptic-Dynamic Meteorology in Midlatitudes. Vol. 2, Oxford University Press, New York, 594 pg., 1993.

BONATTI, J. P. ; RAO, V. B. . Moist Baroclinic Instablity In The Development Of North Pacific And South American Intermediate-Scale Disturbance.. Journal of the Atmospheric Sciences, v. 44, p. 2657-2667, 1987.

CARLSON, T. N. Mid-Latitude Weather Systems. London: Harper Collins, 512pg., 1991.

DA ROCHA, R. P. Impacto de Parametrizações de Convecção em Ciclogênese sobre o Oceano. Tese de Doutorado em Meteorologia. INPE-7505-TDI/720, 1999.

DUNBAR, R. S.; LUNGU, T.; WEISS, B.; STILES, B.; HUDDLESTON, J.; CALLAHAN, P.S.; SHIRTLIFFE, G.; PERRY, K. L., HSU, C.; MEARS, C.; WENTZ, F., SMITH, D.. QuikSCAT Science Data Product User's Manual, Version 3.0, JPL Document D-18053 - Rev A, Jet Propulsion Laboratory, Pasadena, CA, 2006.

FORD, R. P.; MOORE, W. K. Secondary Cyclogenesis - Coparison of Observation and Theory. Monthly Weather Review, v. 118, p. 427-446, 1990.

GAN, M.A. Ciclogêneses e Ciclones sobre a América do Sul. Tese de Doutorado em Meteorologia, INPE-5400-TDI/479, 1992.

GAN, M. A.; RAO, V. B. Case Studies of Cyclogenesis over South America. Meteorological Applications, v. 3, p. 359368, 1996.

HOSKINS, B. J.; HODGES, K. I. A New on Southern Hemisphere Storm Tracks. Journal of Climate, v. 18, p. 4108-4129, 2005.

HOSKINS, B. J.; MCINTYRE, M. E.; ROBERTSON, W. On the use and significance of isentropic potential vorticity maps, Quarterly Journal of Royal Meteorological Society, v. 111, n. 470, p. 877-946, 1985.

HUO, Z.; ZHANG, D. -L.; GYAKUM, J. The cycle of intense IOP-14 storm dring CASP II - PartII: sensitivity experiments. Atmosphere-Ocean, v. 34, n. 1, p. 81-102, 1996.

IWABE, C. M. N. Intrusão estratosférica associada com ciclogêneses na costa do sul do Brasil: uma análise utilizando o conceito de vorticidade potencial. Dissertação de Mestrado em Meteorologia, Instituto de Astronomia, Geofísica e Ciências Atmosféricas - IAG-USP, 106 pg, 2008.

KALNAY, E. et al. NCEP/NCAR 40-year Reanalysis Project. Bulletin of the American Meteorological Society, v. 77, p. 437-471, 1996.
KOUSKY, V. E.; ELIAS, M. Meteorologia Sinótica: Parte I. INPE-2605-MD/021, São José dos Campos, 118 pg., 1982.

KUO, Y. -H.; LOW-NAM S. Prediction of nine explosive cyclones over the western Atlantic ocean with a regional model. Monthly Weather Review, v. 118, p. 3-25. 1990.

KUO, Y. -H.,; REED, R. J.; LOW-NAM, S. Effects of Surface Energy during the early Development and Rapid Intensification Stages of Seven Explosive Cyclones in the Western Atlantic. Monthly Weather Review, v. 119, p. 457-476, 1991.

LENTERS, J. D.; COOK, K.H. On the Origin of the Bolivian High and Related Circulation Features of the South American Climate. Journal of the Atmospheric Sciences, v. 54, p. 656-677, 1997.

MARENGO, J. A.; ROGERS, J. C. Polar Air Outbreaks in the Americas: Assessments and Impacts During Modern and Past Climates. In: Interhemispheric Climate Linkages. Ed. MARKGRAF, V., San Diego: Academic Press, p. 3151, 2001.

MARENGO, J. A.; SOARES, W. R.; SAULO, C.; NICOLINI, M. Climatology of the Low-Level Jet East of the Andes as Derived from NCEP-NCAR Reanalyses: Characteristics and Temporal Variability. Journal of Climate, v. 17, n. 12, p. 2261-2280, 2004.

McTAGGART-COWAN, R.; BOSART, L.; DAVIS, C. A.; ATALLAH, E. H.; GYAKUM, J. R. ; EMANUEL, K. A. Analysis of Hurricane Catarina (2004), Monthly Weather Review, v. 134, p. 3029-3053, 2006.

MIKY FUNATSU, B., GAN, M. A.; CAETANO, E. A case study of orographic cyclogenesis over South America. Atmósfera, v. 17, n. 2, p. 91-113, 2004.

NIETO, R.; GIMENO, L.; TORRE, L.; RIBERA, P.; GALLEGO, D.; HERRERA, R. G.-; GARCIA, J. A; NUÑEZ, M.; REDAÑO, A.; LORENTE, J. Climatological features of cutoff low systems in the Northern Hemisphere, Journal of Climate, v. 18, p. 3085-3103, 2005.

ODA, T. O. Efeitos da Distribuição Espaço-Temporal da Temperatura do Mar no Desenvolvimento de Ciclones Extratropicais. Tese de Doutorado em Meteorologia, UFRJ, Rio de Janeiro, 125 pg., 2005.

PETTERSSEN, S. Weather analysis and forecasting, Vol. I: Motion and motion systems, New York, McGraw Hill Book Co. Inc. 428 pg., 1956.

PIVA, E. Estudo de caso sobre o papel dos fluxos de calor latente e sensível em superfície em processos de ciclogênese de costa leste ocorrido na costa da América do Sul. Dissertação de Mestrado em Meteorologia, Instituto Nacional de Pesquisas Espaciais, INPE-8498-TDI/781, 162 pg, 2001. 
REBOITA, M. S. Normais Climatológicas Provisórias de Rio Grande, no período de 1991 a 2000. Monografia de Graduação em Bacharelado em Geografia, 2001.

REBOITA, M. S. Ciclones Extratropicais sobre o Atlântico Sul: Simulação Climática e Experimentos de Sensibilidade. Tese de Doutorado em Meteorologia, Instituto de Astronomia, Geofísica e Ciências Atmosféricas - IAG-USP, 359 pg., 2008.

REBOITA, M. S.; da ROCHA, R. P.; AMBRIZZI, T. Climatologia de Ciclones sobre o Atlântico Sul Utilizando Métodos Objetivos na Detecção destes Sistemas. In: IX CONGREMET, Congresso Argentino de Meteorologia, Buenos Aires, AR, Outubro 3-7, 2005.

REED, R. J. A study of a characteristic type of upper-level frontogenesis. Journal of Meteorology., v. 12, p. 226-237, 1955.

REED, R. J.; SIMMONS, A. J. Numerical simulation of an explosively deepening cyclone over the north Atlantic that was unaffected by concurrent surface energy fluxes. Weather and Forcasting, v. 6, n. 1, p. 117-122, 1991:

REX, D. F. Blocking action in the middle troposphere and its effect upon regional climate. Part I: An aerological study of blocking action. Tellus, v. 2, p. 196-211, 1950a.

REX, D. F. Blocking action in the middle troposphere and its effect upon regional climate. II. The climatology of blocking action. Tellus, vol 2, p. 275-301, 1950b.
SATYAMURTY, P.; SANTOS R. P.; LEMS, M. A. M. On the stationary trough generated by the Andes. Monthly Weather Review, v. 108, p. 510-520, 1980.

SELUCHI, M. Diagnóstic Y Prognóstico de Situaciones Sinópticas Conducentes a Ciclogénesis sobre el Este de Sudamérica. Geofísica International, v. 34, n. 2, p. 171186, 1995.

SELUCHI, M. E.; CALBETE, N. O.; ROZANTE J. R. Análisis de Un Desarrollo Ciclónico en la Costa Oriental de América Del Sur. Revista Brasileira de Meteorologia, v. 16, n. 1, p. 51-65, 2001.

SINCLAIR, M. R. An Objective Cyclone Climatology for the Southern Hemisphere. Monthly Weather Review, v. 122, p. 2239-2256, 1994.

SINCLAIR, M. R. Reply. Monthly Weather Review, v. 124, p. 2615-2618, 1996.

SUTCLIFFE, R. C. A Contribution to the Problem of Development. Quarterly Journal of Royal Meteorological Society, v. 73, p. 370-383, 1947.

VERA, C. S.; VIGLIAROLO, P. K.; BERBERY, E. H. Cold Season Synoptic-Scale Waves over Subtropical South America. Monthly Weather Review, v. 130, p. 684-699, 2002. 